REsumo
A partir de sua experiência cli-
nica em diversos campos de atu-
ação, a autora visa a refletir
sobre apsiquiatrização do dis-
curso e a medicalização na in-
fância. Indaga de que modo o
saber médico-psiquiátrico foi res-
pondendo às demandas sociais
a ele endereçadas, cuja respos-
ta, atualmente, se reduziu ao
diagnóstico do desvio comporta-
mental e sua tentativa de nor-
matização, via medicação. Para
tanto, retoma a história da psi-
quiatria infantil e da clinica
médica com crianças, discutindo
de que modo o discurso médico-
psiquiátrico, através de seusdis-
positivos disciplinares, vem sen-
do convocado a responder sobre
o mal-estar que a infância in-
troduz no projeto social na atua-
lidade.
Descritores: psiquiatrização
do discurso; medicalização; in-
fância.
and

\section{A FABRICAÇÃO DA LOUCURA NA INFÂNCIA: PSIQUIATRIZAÇÃO DO DISCURSO E MEDICALIZAÇÃO DA CRIANÇA}

Michele Kamers

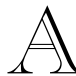

temática relativa à psiquiatrização do discurso e à medicalização na infância se colocou a nós a partir da atuação em um projeto denominado "Serviço Infantil" - no qual realizamos, conjuntamente com uma equipe composta por vários profissionais, um trabalho de escuta na modalidade de grupo de pais, de crianças e de adolescentes -, de nossa atividade como supervisora do Cen-

Psicanalista, professora do Departamento de Psicologia da Universidade Regional de Blumenau (FURB) e do Curso de Psicologia do Instituto Blumenauense de Ensino Superior (IBES-SOCIESC). Coordenadora do Serviço Infantil e da Pós-Graduação em Psicologia Hospitalar e da Saúde do Hospital Santa Catarina, Blumenau, SC, Brasil. 
tro de Atenção Psicossocial Infantil (CAPS Infantil) e do trabalho desenvolvido com crianças e adolescentes em nossa clínica privada.

Por meio destes três campos de atuação, percebemos que a lógica circunscrita em torno dos encaminhamentos realizados pelas diversas instâncias que demandam tratamento para a criança consiste em um ciclo repetitivo: a escola, confrontada com as dificuldades de aprendizagem ou indisciplina da criança, solicita à família uma intervenção. Diante da "dita" insuficiência da intervenção parental, a escola, ou encaminha a criança ao neuropediatra ou psiquiatra infantil, ou aciona o conselho tutelar, alegando negligência familiar. Em nossa experiência no consultório privado, em que atendemos uma clientela de nível socioeconômico mais favorecido, a situação não é muito diferente, com exceção de um aspecto: a vulnerabilidade frente à tutela e vigilância do Estado. Nesse caso, as crianças são encaminhadas pela escola ao psicólogo, que, por sua vez, encaminha a criança ao neuropediatra, que prescreve a medicação geralmente ritalina, concerta ou risperidona. Em outras ocasiões, a escola nem chega a encaminhar ao psicólogo, mas diretamente ao neuropediatra ou psiquiatra infantil, que identifica na criança um quadro de TDAH (Transtorno de Deficit de Atenção e Hiperatividade), ou de transtorno opositivo, prescrevendo o tratamento farmacológico.

As situações acima mencionadas nos permitem efetuar as seguintes considerações: 1) a escola tem se tornado o dispositivo regulador da inclusão/exclusão da criança no domínio do saber médico-psiquiátrico; 2) o saber e a intervenção médica e farmacológica são assegurados pelos dispositivos sociais disciplinares, tais como as escolas, as unidades de saúde e as clínicas privadas; 3 ) a medicação tornou-se a principal forma de tratamento utilizada pela medicina para responder às demandas sociais realizadas, fundamentalmente, pelas instituições de assistência à infância.

Trata-se de constatações que nos levam a refletir sobre a função que a medicalização da criança - entendida como dispositivo médico-disciplinar vem cumprindo para as instituições de assistência à infância na atualidade.

\section{Das ilusões psicopedagógicas ao Real do discurso médico-psiquiátrico}

Com base nas considerações apresentadas, percebemos que houve um deslocamento do olhar assistencial, psicológico e educativo sobre a criança para o campo da intervenção médico-psiquiátrica, na medida em que a medicina 
vem se constituindo como o dispositivo regulador do normal e do patológico sobre a criança na atualidade.

Como sabemos, originariamente, a tentativa de encontrar a gênese da loucura do adulto na criança culminou na construção de dispositivos higienistas de vigilância e controle sobre a família e preceitos sobre o cuidado com a criança. Nesse sentido, uma de nossas questões consiste em indagar se, atualmente, esta função não estaria sendo delegada ao campo da assistência social e psicológica, cabendo ao médico, única e exclusivamente, decidir sobre a patologia em causa e prescrever a medicação para a criança. E mais, de que modo, contemporaneamente, esses dois discursos - o da assistência psicológica, pedagógica e social e o da intervenção médico-psiquiátrica - se entrecruzam e se retroalimentam, formando uma rede na qual, a partir do momento em que a criança e sua família são capturadas, não conseguem mais sair, reduzindo a criança a uma linhagem médica alheia, que não contempla seus laços sociais e familiares?

A esse respeito, Vorcaro (2011) sustenta que

A infância tornou-se objeto de disputa de poderes, configurada como uma zona limítrofe de confronto entre o público e o privado, gerando novos saberes e modalidades de controle. O cuidado com as crianças ultrapassou família e escola, sendo abarcado pelo discurso médico sobre a infância. (p. 220)

Nesse sentido, nos cabe indagar de que modo o saber médicopsiquiátrico foi respondendo às demandas sociais a ele endereçadas, cuja resposta, atualmente, se reduziu ao diagnóstico do desvio comportamental e sua tentativa de normatização, via medicação, delegando aos outros especialistas a assistência à família e à criança.

O fato é que, contemporaneamente, observa-se que a práxis médico-psiquiátrica na infância prescinde completamente da escuta da narrativa dos pais sobre seus filhos, localizando o olhar médico, exclusivamente, nas sintomatologias apresentadas pela criança, cuja causa é atribuída a uma falha no real do corpo, mais precisamente a uma falha no funcionamento cerebral e seus mecanismos neuroquímicos, o que, aliás, justifica e fundamenta a medicalização.

Nos dias atuais, o aumento do número de diagnósticos na infância, especialmente o de TDAH, e a consequente medicalização da criança em idade escolar, tem tomado proporções tais que podemos defini-lo como uma verdadeira epidemia. Segundo Jerusalinsky (2011), antes do TDAH estas mesmas crianças eram situadas na categoria da Disfunção Cerebral Mínima. Mas, a partir de 1994, com a modifica- 
ção do DSM-III e a publicação do DSM-IV, houve um deslocamento do campo dos problemas psíquicos para o dos transtornos, declarados neste manual como tendo, fundamentalmente, uma etiologia genética e bioquímica, na qual o sofrimento psíquico da criança é interpretado como um transtorno neurobiológico com signos inespecíficos, constituindo uma perigosa transformação do campo da psicopatologia na infância: o apagamento do sujeito em sua dimensão psíquica, histórica e social - em que a medicina se eleva à condição divina.

De acordo com Graeff e Vaz (2008), o TDAH, o transtorno desafiador opositivo e o transtorno de conduta lideram a lista dos transtornos mais diagnosticados por neuropediatras e psiquiatras infantis na atualidade, sendo a prevalência destes estimada em $3 \%$ a $6 \%$ da população infantil e, dependendo do critério utilizado, podendo chegar a $26 \%$ da mesma população, constituindo uma estimativa alarmante. Chama a atenção que a maior parte desses diagnósticos seja aplicada a crianças em idade escolar, o que nos leva a indagar de que modo a escola tem agenciado a inclusão da criança no domínio do saber médico-psiquiátrico. Para Guarido (2007), a psicologização da escola tem cedido lugar à psiquiatrização do discurso escolar, o que foi promovido pelo advento do DSM-III e pelos avanços da medicalização como forma "hegemônica" de intervenção terapêutica na atualidade. 
A lógica implícita no DSM-IV leva a uma verdadeira inversão do procedimento psiquiátrico: é a produção dos medicamentos que determina a fabricação de diagnósticos. "Há aí uma inversão não pouco assustadora, pois na lógica atual de construção diagnóstica, o remédio participa da nomeação do transtorno" (Guarido, 2007, p. 154), constituindo um verdadeiro dispositivo de fabricação da loucura.

A ligeireza (e imprecisão) com que as pessoas são transformadas em anormais é diretamente proporcional à velocidade com que a psicofarmacologia e a psiquiatria contemporânea expandiram seu mercado. Não deixa de ser surpreendente que o que foi apresentado como avanço na capacidade de curar tenha levado a ampliar em uma progressão geométrica a quantidade de doentes mentais. (Jerusalinky \& Fendrik, 2011, p. 6)

Segundo os mesmos autores, a aplicação do DSM-IV tem produzido ao menos três falsas epidemias: o Transtorno Bipolar, o Transtorno de Deficit de Atenção e Hiperatividade e o Autismo Infantil - o que constitui um grave problema com consequências assustadoras, na medida em que este dispositivo não apenas informa sobre a doença, mas ele a produz, conduzindo a um inevitável processo de psicopatologização da infância e medicalização da criança na atualidade.

Trata-se de uma clínica dogmaticamente reducionista que se transforma cada vez mais numa neurobiologia. Reduzir suas causalidades ao metabolismo das catecolaminas, a clí- nica vai se limitar ao arsenal químico, também reduzido, apesar da proliferação de novos nomes sempre lançados com a mesma pirotecnia mercadológica com que se lançam novos sabonetes ou pastas dentifrícias. (Infante, 2011, p. 64)

Por serem deliberadamente ateóricos, os manuais diagnósticos se voltam para uma descrição que seja partilhada pela maioria dos psiquiatras do mundo. Deste modo, qualquer hipótese etiopatogênica é excluída, constituindo uma nosografia sem sujeito (Quinet, 2009), o que podemos definir como um processo de desaparecimento da psicopatologia - o que implica uma teoria sobre o sofrimento psíquico e uma hipótese etiológica - produzido pelo advento do DSM.

Segundo Scheinkman (1993) a introdução do tratamento farmacoquímico na psiquiatria obrigou os médicos e psiquiatras a retomarem os modelos biológicos, circunscritos em torno de uma causalidade biológica, genética e neuroquímica do transtorno, o que na história da psiquiatria poderia ser pensado como uma negação da tese kraepeliniana - em que "o quadro psicopatológico não pode em nenhum caso ser concebido como uma expressão direta de um processo mórbido de natureza biológica" (Pereira, 2009a, p. 163) - e a retomada do espírito inaugurado por Bayle, que introduziu na tradição francesa a concepção biológica no campo da psiquiatria (Pereira, 2009b).

Atualmente, a medicação tem sido utilizada não apenas como a prin- 
cipal forma de "tratamento da criança" mas como dispositivo de vigilância e controle que as instâncias tutelares realizam sobre a família e a criança na atualidade. Nesse contexto, partimos da hipótese de que são precisamente os dispositivos assistenciais e tutelares que demandam, autorizam e asseguram a intervenção médico-psiquiátrica sobre a criança. Para Foucault (1961), não foi a medicina que definiu os limites entre a razão e a loucura, mas, desde o século XIX, os médicos foram encarregados de vigiar a fronteira e de guardá-la. Isto é, a necessidade imperiosa de separar os desviantes da esfera social exigiu a entrada em cena de um saber especializado, o do médico, responsável pelo estabelecimento dos limites entre a razão e a loucura. É neste ponto preciso que a tutelarização do "desviante" pelo poder jurídico do Estado passou às mãos da medicina (Castel, 1978).

\section{A psiquiatria infantil e a clínica médica com crianças}

A clínica médica com crianças se iniciou a partir de uma reflexão sobre a deficiência mental, primordialmente, a partir do surgimento das primeiras instituições para deficientes na Europa. Seus precursores foram médicos-pedagogos ou reeducadores das insuficiências sensoriais e dos retar- damentos (Pessotti, 1984), estando claramente vinculada ao campo da educação especial e, mais especificamente, da medicina moral. Neste campo, a deficiência foi concebida como um problema a ser tratado pelo médico, a quem caberia alterar hábitos através de uma ortopedia mental ou ortofrenia.

Segundo Ajuriaguerra (1972), a psiquiatria infantil tem uma história recente. Até o século XX não havia nada que pudesse ser nomeado como psiquiatria infantil, apesar de suas raízes encontrarem-se nas experiências pedagógicas realizadas com deficientes mentais e sensoriais. Para Bercherie (2001), embora a clínica com a criança, com seus conceitos específicos, só tenha se estabelecido a partir de 1930, seu campo de investigação é tão antigo quanto o da psiquiatria de adultos.

Por meio de clássicos como Ariès (1981), Badinter (1985), Donzelot (1986) e Postman (1999), sabemos que a noção de infância, enquanto idade da vida em que se reconhecem particularidades que permitem diferenciar adultos e crianças, é tributária de um processo de moralização promovido pelos reformadores da Igreja e do Estado, que instituiu a escolarização como dispositivo de inclusão/exclusão da criança na vida societária. Nesse contexto, família e escola se converteram em principais lócus de vigilância da criança a partir da Modernidade. 
Para esses reformadores, a educação da criança não poderia ser deixada à mercê e arbítrio dos pais. Em nome do bem-estar da criança, vem tomar lugar, sob diversas figuras, um terceiro social, representado pelos especialistas encarregados de dizer sobre como se deve educar e criança (Kamers, 2006). Enquanto a conjugalidade tornou-se cada vez mais privada e discreta, a parentalidade passou ao domínio público (Julien, 2000), transformando a criança em objeto de disputa de diversos saberes e poderes, instituindo a infância em uma zona limítrofe entre o público e o privado, tornando a criança e sua família objetos privilegiados de vigilância e controle por parte do Estado.

Nesse contexto, a autoridade paterna foi usurpada pelo discurso técnico-especializado. Entretanto, os especialistas encarregados de reeducar terapeuticamente a família dão-se conta de que a desestruturação familiar é um fato social, mas raramente percebem que as terapêuticas educativas são componentes ativos na fabricação deste fato (Costa, 1999).

O território da intimidade familiar constituiu-se como um refúgio de proteção da criança frente às exigências sociais, o que segundo Lebrun (2010) produziu uma fratura entre o funcionamento social e o funcionamento da família, em que esta assume uma posição de antagonismo ao social, na medida em que os pais, estando identificados com a criança, tentam livrá-la e "livrar-se" dos cons- 
trangimentos impostos pelo processo civilizatório. Nesse sentido, se pais e filhos encontram-se em uma posição de igualdade no interior da família, nos parece inevitável que um terceiro "social" seja convocado a introduzir algum tipo de ordenamento nesta "fratria" familiar.

A educação e a escolarização passaram a ser instituídas como as principais garantias da ordem pública, determinando que a criança fosse elevada à condição de objeto privilegiado de vigilância e de escolarização (Ariès, 1981; Bercherie, 2001; Postman, 1999). Trabalho e escola se converteram em dispositivos de inclusão/exclusão do sujeito na ordem societária.

Enquanto que na psiquiatria de adultos a noção de doença mental só se tornou possível a partir da noção de liberdade individual, na qual os indivíduos passaram a ser um empecilho para a ordem social e moral vigente (Ey, Bernard \& Brisset, n.d.), a psiquiatria infantil se constituiu como campo e lócus privilegiado de busca da etiologia da loucura do adulto na criança a partir da publicação dos primeiros tratados de psiquiatria na segunda metade do século XIX. Trata-se de um período marcado pelas concepções de Falret e Morel, que estabeleceram a diferença entre doença mental hereditária e adquirida.

Para Bercherie (2001), os conceitos de Morel vão dirigir a atenção para a infância dos alienados, introduzindo a necessidade de buscar na criança a causa da loucura do adulto. De acordo com Ajuriaguerra (1972), a preocupação com a infância determinou o surgimento dos primeiros centros de reeducação para delinquentes juvenis e foram criadas as primeiras instituições para crianças em perigo moral. A família, mais do que a criança, tornou-se o verdadeiro lugar da doença e a medicina foi convocada a reeducar terapeuticamente a família e a responder sobre o mal-estar na infância.

\section{A medicina e os dispositivos tutelares}

Donzelot (1986) denomina de polícia das famílias os dispositivos de controle da normalidade social e familiar delegados à medicina. Para ele, enquanto os textos do século XVIII se limitavam aos conselhos educativos, visando à prática dos hospícios de menores abandonados, à criança cuidada por amas de leite e à educação das 
crianças ricas, os textos médicos do século XIX mudaram de tom e se tornaram imperativos. O médico assumiu o lugar de agente tutelar das famílias, principalmente das classes menos favorecidas.

No interior dessas camadas sociais eles visam um alvo privilegiado, a patologia da infância na sua dupla forma: a infância em perigo, aquela que não se beneficiou de todos os cuidados da criação e da educação almejados, e a infância perigosa, a da delinqüência. (Donzelot, 1986, p. 92)

Nesse contexto, o discurso médico-psiquiátrico, através de seus dispositivos disciplinares, é convocado a detectar e responder a qualquer entrave que a criança possa representar ao projeto social. "Assim, ao mal-estar provocado pela criança, que não pode ser reconhecido pelo saber pediátrico, pedagógico ou parental, a clínica psiquiátrica diagnostica" (Vorcaro, 2011, p. 221).

Segundo Donzelot (1986) o saber psiquiátrico busca recobrir e neutralizar todo tipo de desadaptação da criança, mediante toda uma estrutura de prevenção assumida pelos especialistas. Entretanto, "como continuar a pretender que a prevenção nada mais tem a ver com o exercício de um poder repressivo, quando ela é mandatada judicialmente para penetrar no santuário familiar, podendo mobilizar, se necessário a força policial?” (p. 93).

A partir de Vorcaro (2011), podemos compreender que o diagnóstico psiquiátrico visa a responder a "isso" que não é reconhecível pelo ideal parental e social e indicar terapêuticas que sustentem a promessa de reconduzir a criança à "normalidade" ou que, adaptando-a, possam aliviar o mal-estar que a infância produz ao projeto social e, assim, sustentá-lo.

$\mathrm{Na}$ medida em que a criança hoje é portadora dos ideais sociais do adulto, podemos pensar que o que está em cena é justamente um apagamento da infância e a tentativa de transformação de um real infantil num modo ideal de existência adulta. Sendo assim, a resposta não esperada, bem como aquela esperada, mas dada fora de tempo, são consideradas como expressão de uma patologia na criança (Lajonquière, 1999).

\section{Da tentativa de apagamento do Real ao retorno do recalcado sob a forma de patologia}

No clássico "O mal-estar na civilização”, Freud (1930/1996) é categórico ao afirmar que nunca dominaremos a natureza e nosso corpo, com limitada capacidade de adaptação e realização. A impossibilidade apontada por Freud nos permite afirmar que, se o mal-estar é uma condição própria do humano, trata-se de refletir de que modo, em cada momento histórico, a civilização lida com este mal-estar.

Atualmente, o discurso médicopsiquiátrico sustenta a promessa de 
que o mal-estar poderia ser codificado em doença e para cada doença haveria um medicamento específico, o que no caso da infância poderia ser pensado como a tentativa de apagar a condição pulsional da criança. Ora, se num outro momento da história a educação consistia no processo de regulação da instância pulsional da criança através do processo civilizatório, nos parece que atualmente, diante da impossibilidade de reconhecer esse resto que Lacan (1988) chama de impossível, esse real rechaçado retorna sob a forma de patologia.

Essa lógica instaurada na Modernidade, a ilusão de controle daquilo que Freud chama de impossibilidade e Lacan de impossível, nos parece ser o mecanismo que torna o uso da medicação como a grande promessa do século XXI. Trata-se de um dispositivo de nomeação do mal-estar, sua classificação e apresentação do fármaco específico para combatê-lo.

O aumento assustador de crianças diagnosticadas com transtornos das mais variadas formas, assim como a psiquiatrização do discurso familiar e escolar, nos permitem assinalar que "a diferença entre adultos e crianças aparece nublada com a aplicação do paradigma da psiquiatria biológica. No campo do orgânico, as diferenças entre adultos e crianças praticamente inexistem, já que neste a dimensão histórica está ausente" (Guarido, 2007, p. 156). O que nos permite pensar que, se atualmente o discurso médico-psiquiátrico converteu-se no principal dispositivo regulador do normal e do patológico na infância, isso se dá graças às instituições de assistência à infância - a família, a escola, o conselho tutelar, as clínicas privadas, as unidades de saúde - que demandam à medicina uma intervenção medicamentosa sobre a criança. Dito de outro modo, em nome de "A Criança" idealizada pelo projeto social, se colocam todas as pequenas crianças em risco (Lajonquière, 2010).

Essa tentativa de apagamento do Real, desse resto implicado em todo ato educativo (Lajonquière, 1999), poderia ser pensado como a substituição do significante loucura, enquanto representante da representação da relação do homem com seus fantasmas e com seu impossível, pelo significante doença mental, que consiste em uma forma de neutralização e apagamento da dimensão da loucura, da dimensão pulsional do sujeito, a fim de que a sociedade possa prever para cada sujeito um modo de neutralização que lhe convém (Foucault, 2010). 
Diante do exposto, Foucault (2010) salienta que não restará nada mais do que as técnicas da medicina, explicando que o suporte técnico dessa mutação consiste na promessa da medicina de dominar a doença mental como uma afecção orgânica, no controle farmacológico do sujeito e no apagamento de seus sintomas, na definição rigorosa dos "desvios de comportamento", a fim de que a sociedade possa neutralizar o sujeito. Nenhuma dessas técnicas suprimirá a doença mental, mas sua consequência será apagar de nossa cultura a face da loucura. Entretanto, Foucault nos adverte de que os progressos da medicina poderão de fato fazer desaparecer a doença mental, assim como a lepra e a tuberculose, mas uma coisa permanecerá: a relação do homem com seus fantasmas e com seu impossível.

Sobre este aspecto, Roudinesco (2000) salienta que, ao tentar banir de seu horizonte a realidade do infortúnio, da morte e da violência, a sociedade democrática elegeu o fármaco como princípio fundamental de apaziguamento do malestar próprio à condição da existência. "Não surpreende, portanto, que a infelicidade que fingimos exorcizar retorne de maneira fulminante no campo das relações sociais e afetivas” (p. 17), havendo apenas uma substituição das camisas de força pela redoma medicamentosa, constituindo uma verdadeira fabricação da loucura na infância. 
THE MADNESS FABRICATION IN CHILDHOOD: PSYCHLATRIZATION OF DISCOURSE AND CHILDREN MEDICALIZATION

\section{Abstract}

Based on her clinical experience in several fields, the author proposes to reflect about psychiatrization of discourse and children medicalization. She questions how the psychiatric knowledge has been responding to social demands; the current response is merely a diagnosis of behavioral deviations and an attempt of standardization by medication. This article presents children psychiatry and medical clinic with children history, discussing how the psychiatric medical discourse, through its disciplinary mechanisms, has been summoned to respond to the malaise that childhood introduces in the social project today.

Index Terms: psychiatrization of discourse; medicalization; childhood.

LA FABRICACIÓN DE LA LOCURA EN LA INFANCIA: PSIQUIATRIZACIÓN DEL DISCURSO Y MEDICALIZACIÓN DEL NIÑO

\section{RESUMEN}

A partir de la experiencia clínica en diversos campos de actuación, la autora reflexiona sobre la psiquiatrización del discurso y la medicalización de la infancia. Indaga de qué forma el saber psiquiátrico fue respondiendo a las demandas sociales que se le dirigieron, cuya respuesta, actualmente, se limitó al diagnóstico de la desviación del comportamiento y el intento de normalización, por medio de la medicación. Para esto, retoma la bistoria de la psiquiatría infantily de la clínica médica con niños y niñas, discutiendo de qué manera el discurso médico-psiquiátrico, a través de sus dispositivos disciplinarios, ha sido convocado a responder sobre el malestar que la infancia introduce en el proyecto social en la actualidad.

Palabras clave: psiquiatrización del discurso; medicalización; infancia.

\section{REFERÊNCIAS}

Ajuriaguerra, J. de (1972). Manual de psiquiatría infantil. Barcelona: Masson.

Ariès, P. (1981). História social da criança e da família (D. Flaksman, Trad.). Rio de Janeiro: Jorge Zahar.

Badinter, E. (1985). Um amor conquistado: o mito do amor materno (W. Dutra, Trad.). Rio de Janeiro: Nova Fronteira.

Bercherie, P. (2001). A clínica psiquiátrica da criança: estudo histórico. In O. Cirino, Psicanálise e psiquiatria com crianças: desenvolvimento ou estrutura (pp. 127-144). Belo Horizonte: Autêntica.

Castel, R. (1978). A ordem psiquiátrica: a idade de ouro do alienismo (M. T. da Costa Albuquerque, Trad.). Rio de Janeiro: Graal.

Costa, J. F. (1999). Ordem médica e norma familiar. Rio de Janeiro: Graal.

Donzelot, J. (1986). A polícia das famílias (M. T. da Costa Albuquerque, Trad., 2a ed.). Rio de Janeiro: Graal.

Ey, H., Bernard, P. \& Brisset, C. (n.d.). Manual de psiquiatria (5a ed.). Rio de Janeiro: Masson.

Foucault, M. (1961). Folie et Déraison. Histoire de la Folie à l'áge Classique. Paris: Plon.

Foucault, M. (2010). Problematização do sujeito: psicologia, psiquiatria, psicanálise (V. L. A. Ribeiro, Trad.). Rio de Janeiro: Forense Universitária.

Freud, S. (1996). O mal-estar na civilização. In S. Freud, Edição standard brasileira das obras psicológicas completas de Sigmund Freud (J. Salomão, Trad., Vol. 21, pp. 73-148). Rio de Janeiro: Imago. (Trabalho original publicado em 1930)

Guarido, R. (2007, janeiro/abril). A medicalização do sofrimento psíquico: considerações sobre o discurso psiquiátrico e seus efeitos na educação. Educação e pesquisa, 33(1), 151-161.

Graeff, R. L. \& Vaz, C. E. (2008, setembro/ dezembro). Personalidade de crianças com 
Transtorno de Déficit de Atenção e Hiperatividade (TDAH) por meio do Rorschach. Psicologia: teoria e pesquisa, 22(3), 269-276.

Infante, D. P. (2011). Psiquiatria para que e para quem? In A. Jerusalinsky \& S. Fendrik (Orgs.), O livro negro da psicopatologia contemporânea (pp. 63-72). São Paulo: Via Lettera.

Jerusalinsky, A. (2011). Gotinhas e comprimidos para crianças sem história: uma psicopatologia pós-moderna para a infância. In A. Jerusalinsky \& S. Fendrik (Orgs.), O livro negro da psicopatologia contemporânea (pp. 231-242). São Paulo: Via Lettera.

Jerusalinsky, A. \& Fendrik, S. (2011). Introdução. In A. Jerusalinsky \& S. Fendrik (Orgs.), O livro negro da psicopatologia contemporânea (pp. 5-10). São Paulo: Via Lettera.

Julien, P. (2000). Abandonarás teu pai e tua mãe (P. Abreu, Trad.). Rio de Janeiro: Companhia de Freud.

Kamers, M. (2006). As novas configurações da família e o estatuto simbólico das funções parentais. Estilos da Clínica, 11(21), 108-125.

Lacan, J. (1988). O seminário, livro 11: os quatro conceitos fundamentais da psicanálise (M. D. Magno, Trad.). Rio de Janeiro: Jorge Zahar. Lajonquière, L. de (1999). Infância e ilusão (psico)pedagógica: escritos de psicanálise e educação. Petrópolis, RJ: Vozes.

Lajonquière, L. de (2010). Figuras do infantil: a psicanálise na vida cotidiana com as crianças. Petrópolis, RJ: Vozes.

Lebrun, J.-P.(2010). O mal-estar na subjetivação. Porto Alegre: CMC.

Pereira, M. E. C. (2009a). Kraepelin e a questão da manifestação clínica das doenças mentais. Revista latinoamericana de psicopatologia fundamental, 12(1), 161-166. Recuperado em 1 de março, 2012, de SciELO (Scientific Electronic Library Online): http://www.scielo.br/

Pereira, M. E. C. (2009b). Bayle e a descrição da aracnoidite crônica na paralisia geral: sobre as origens da psiquiatria biológica na França. Revista latinoamericana de psicopatologia fundamental, 12(4), 743-751.
Recuperado em 1 de março, 2012, de SciELO (Scientific Electronic Library Online): http://www.scielo.br/

Pessotti, I. (1984). Deficiência mental: da superstição à ciência. São Paulo: Edusp.

Postman, N. (1999). O desaparecimento da infancia (S. M. de A. Carvalho \& J. L. de Melo, Trads.). Rio de Janeiro: Graphia.

Quinet, A. (2009). Psicose e laço social: esquizofrenia, paranóia e melancolia. Rio de Janeiro: Jorge Zahar.

Roudinesco, E. (2000). Por que a psicanálise? (V. Ribeiro, Trad.). Rio de Janeiro: Jorge Zahar.

Scheinkman, L. (1993). Relações entre medicina e psiquiatria. In J. F. da Silva Filho \& J. A. Russo (Orgs.), Duzentos anos de psiquiatria: coletânea de trabalhos apresentados na Jornada de Psiquiatria do Estado do Rio de Janeiro, 1992 (pp. 109-119). Rio de Janeiro: Relume Dumará; Ed. UFRJ.

Vorcaro, A. (2011). O efeito bumerangue da classificação psicopatológica da infância. In A. Jerusalinsky \& S. Fendrik (Orgs.), O livro negro da psicopatologia contemporânea (pp. 219-229). São Paulo: Via Lettera.

michelekamers@yahoo.com.br Rua Richard Holetz, 30 89010-550 - Blumenau - SC - Brasil.

Recebido em marco/ 2012. Aceito em novembro/ 2012. 